\title{
Crescimento de mudas de angico-vermelho em diferentes volumes de substratos
}

\author{
Talita Baldin ${ }^{1 *}$, Bruno Conte ${ }^{1}$, Luciano Denardi ${ }^{1}$, Rosana de Moraes $^{2}$, Cleber Witt Saldanha ${ }^{2}$ \\ ${ }^{1}$ Universidade Federal de Santa Maria, Av. Roraima n 1000, Cidade Universitária, Bairro Camobi, CEP 97105-900, Santa Maria, RS, Brasil \\ ${ }^{2}$ Fepagro Florestas, BR 287, Acesso VCR 830, km 4,5, Boca do Monte, Caixa Postal 346, CEP 97001-970, Santa Maria, RS, Brasil
}

\author{
"Autor correspondente: \\ talita.baldin@hotmail.com \\ Termos para indexação: \\ Índice de qualidade de Dickson \\ Parapiptadenia rigida \\ Viveiro florestal. \\ Index terms: \\ Dickson quality index \\ Parapiptadenia rigida \\ Forest nursery
}

Histórico do artigo:

Recebido em 27/11/2014

Aprovado em 20/05/2015

Publicado em 30/06/2015

doi: $10.4336 / 2015 . p f b .35 .82 .829$
Resumo - Objetivou-se nesse trabalho avaliar a influência de diferentes volumes de substratos na qualidade de mudas de angico-vermelho (Parapiptadenia rigida (Benth.) Brenan). Foram utilizados tubetes plásticos de seção circular com volume de 50, $100 \mathrm{e}$ $175 \mathrm{~cm}^{3}$. O delineamento experimental adotado consistiu no inteiramente casualizado, com três tratamentos (volume de substrato) e seis repetições. A qualidade das plântulas foi avaliada através dos atributos: altura da parte aérea, diâmetro do colo, número de folhas, biomassa seca aérea e radicular, e biomassa seca total. Através dessas variáveis, foram determinadas as relações: altura/diâmetro do colo, biomassa seca radicular/ biomassa seca aérea, altura/biomassa seca aérea, bem como o índice de qualidade de Dickson. O volume do recipiente influenciou nas características das mudas, visto que as plântulas produzidas em tubetes de maior volume $\left(175 \mathrm{~cm}^{3}\right)$ apresentaram melhor desempenho. A menor dimensão de recipiente $\left(50 \mathrm{~cm}^{3}\right)$ limitou o crescimento das plantas, acarretando em mudas com qualidade inferior.

\section{Growth of angico-vermelho seedlings at different substrates volume}

\section{Introdução}

Historicamente os variados ecossistemas brasileiros sofrem com problemas referentes à degradação ambiental (Brasil, 1998). A preocupação com a crescente diminuição desses ecossistemas tem estimulado pesquisadores ao desenvolvimento de estudos, visando, primordialmente, restabelecer as comunidades naturais de áreas que sofreram degradação.
Nesse cenário, é de fundamental relevância investigações para conhecer e indicar o potencial de espécies florestais, utilizadas para recuperação de áreas degradadas, levando em consideração a diversidade e a versatilidade ecológica das mesmas. Assim, pesquisas vinculadas à produção de mudas são fundamentais para a viabilidade técnica de projetos florestais deste cunho. 
Entre as espécies nativas com potencial uso em reflorestamentos, encontra-se Parapiptadenia rigida (Benth.) Brenan, pertencente à família botânica Fabaceae-Mimosoideae, popularmente conhecida como angico-vermelho, angico-verdadeiro, angelim-amarelo, angico-cedro, dentre outros. A espécie é recomendada para reflorestamentos mistos, em áreas degradadas e de preservação permanente, por apresentar características como facilidade na regeneração natural e caráter agressivo (Vaccaro et al., 1999, Lorenzi, 2002).

O êxito de um plantio florestal depende de inúmeros fatores, dentre os quais a qualidade das mudas, que obrigatoriamente devem estar rustificadas, sadias e bem nutridas, para atingirem inicialmente seu maior potencial produtivo, estando aptas a competirem com ervas daninhas, bem como outras condições adversas encontradas em campo (Lisboa et al., 2012).

No tocante à produção de mudas florestais, Carneiro (1995) expõe que o plantio de espécies nativas, para fins de produção ou conservação, depende, em grande parte, da utilização de mudas produzidas em recipientes. Pesquisas apresentadas por Gomes et al. (2003); Brachtvogel et al. (2006) e Dumroese et al. (2011) comprovam que o tipo de recipiente e suas dimensões exercem influências diretas sobre a qualidade e os custos de produção de mudas.

A espécie florestal é um fator determinante na escolha da dimensão do recipiente; sendo assim, é evidente a necessidade de se estudar qual o volume de substrato mais adequado para cada espécie, uma vez que recipientes maiores ocupam espaços, muitas vezes, desnecessários para a produção de mudas, bem como acarretam dispêndio de substrato e fertilizante (David et al., 2008).

Atualmente, o mercado de insumos florestais oferece tamanhos e formas diferenciadas de recipientes, indicados para várias espécies. No entanto, ainda há carência de informações para a produção de mudas florestais de espécies nativas. Nesse sentido, a pesquisa teve como objetivo avaliar o crescimento inicial de mudas de angico-vermelho em diferentes volumes de substrato.

\section{Material e métodos}

O experimento foi conduzido no município de Santa Maria, distrito de Boca do Monte, RS, no viveiro florestal pertencente à Fundação Estadual de Pesquisa Agropecuária.
Como material propagativo foram utilizadas sementes de angico-vermelho, coletadas no município de Santa Maria, RS, provenientes de cinco árvores matrizes, com potencial germinativo e pureza de 95 e 99,9\%, respectivamente. Foram utilizados três tamanhos de tubetes cônicos, confeccionados em plástico rígido, com capacidade volumétrica de 50 (T50), 100 (T100) e $175 \mathrm{~cm}^{3}$ (T175).

Quanto ao substrato, utilizou-se uma composição padronizada de $50 \%$ de solo peneirado do tipo Argissolo Vermelho Distrófico Arênico (Santos et al., 2013), $25 \%$ de casca de arroz carbonizada, e $25 \%$ de esterco bovino curtido, não sendo utilizada adubação química no substrato.

A semeadura foi realizada diretamente nos tubetes plásticos, adotando-se a padronização de três sementes em cada unidade. Após a semeadura, os tratamentos foram alocados em viveiro, e receberam irrigação por aspersão duas vezes ao dia. Após as plântulas completarem 30 dias, foi efetuado o raleio, com o objetivo de eliminar as excedentes em cada recipiente, deixando apenas a que apresentava maior vigor e posição mais central.

O delineamento experimental adotado foi o inteiramente casualizado, com três tratamentos constituídos pelo volume de substrato (T50, T100, T175) e seis repetições. Cada unidade experimental (repetição) foi constituída por 19 plantas, perfazendo 114 plantas por tratamento.

As avaliações foram realizadas após sete meses da semeadura, onde as seguintes variáveis foram mensuradas: altura da parte aérea $(\mathrm{H}), \mathrm{em} \mathrm{cm}$; diâmetro do colo (DC), em mm; número de folhas (NF); e biomassa seca total (BST), aérea (BSA), radicular (BSR), em g muda ${ }^{-1}$. Com essas variáveis foi possível determinar as relações altura/diâmetro do solo (H/DC), biomassa seca radicular/biomassa seca aérea (BSR/ BSA), altura/biomassa seca aérea (H/BSA) e o índice de qualidade de Dickson (IQD) (Dickson et al., 1960), expresso pela Eq. 1.

$$
\mathrm{IQD}=\frac{\mathrm{BST}}{\mathrm{H} / \mathrm{DC}+\mathrm{BSA} / \mathrm{BSR}}
$$

A altura da parte aérea $(\mathrm{H})$ foi determinada a partir do nível do substrato até a gema apical, com o auxílio de régua graduada em mm, e o diâmetro do colo (DC) foi mensurado no nível do substrato, com o auxílio de paquímetro digital. Para o cálculo da biomassa seca 
radicular (BSR), o sistema radicular das mudas foi submetido ao processo de lavagem, removendo-se o substrato aderido às raízes e, posteriormente, separada da parte aérea (folha e caule) para a determinação da biomassa seca aérea (BSA). Para a biomassa seca total (BST) foram somadas as partes aérea e radicular. Em seguida, o material vegetativo foi seco em estufa de ventilação forçada, a $65{ }^{\circ} \mathrm{C}$ até peso constante (cerca de $72 \mathrm{~h}$ ), e pesado em balança eletrônica com precisão de $0,01 \mathrm{~g}$.

$\mathrm{O}$ experimento foi conduzido em delineamento inteiramente casualizado. Primeiramente foram verificadas a normalidade e homogeneidade de variância dos dados, pressupostos antes de qualquer teste paramétrico. Os dados foram interpretados através da análise de variância (ANOVA) por meio do teste $\mathrm{F}$ a
$5 \%$ de probabilidade. Em caso de rejeição da hipótese nula $\left(\mathrm{H}_{0}\right)$, foi realizado o teste de médias LSD (Least Significant Difference) de Fisher em nível de 5\% de probabilidade para diferenciar os efeitos dos tratamentos.

\section{Resultados e discussão}

Houve efeito significativo $(\mathrm{p}<0,05)$ do volume de substrato para todas as variáveis avaliadas. As mudas conduzidas em recipientes de $175 \mathrm{~cm}^{3}$ apresentaram valores médios significativamente maiores para: altura (H), diâmetro do colo (DC) e biomassa seca aérea (BSA), radicular (BSR) e total (BST). Para a variável número de folhas (NF), não foi detectada diferença $(p<0,05)$ entre os tratamentos T100 e T175, porém, os mesmos diferiram do T50 (Figura 1).
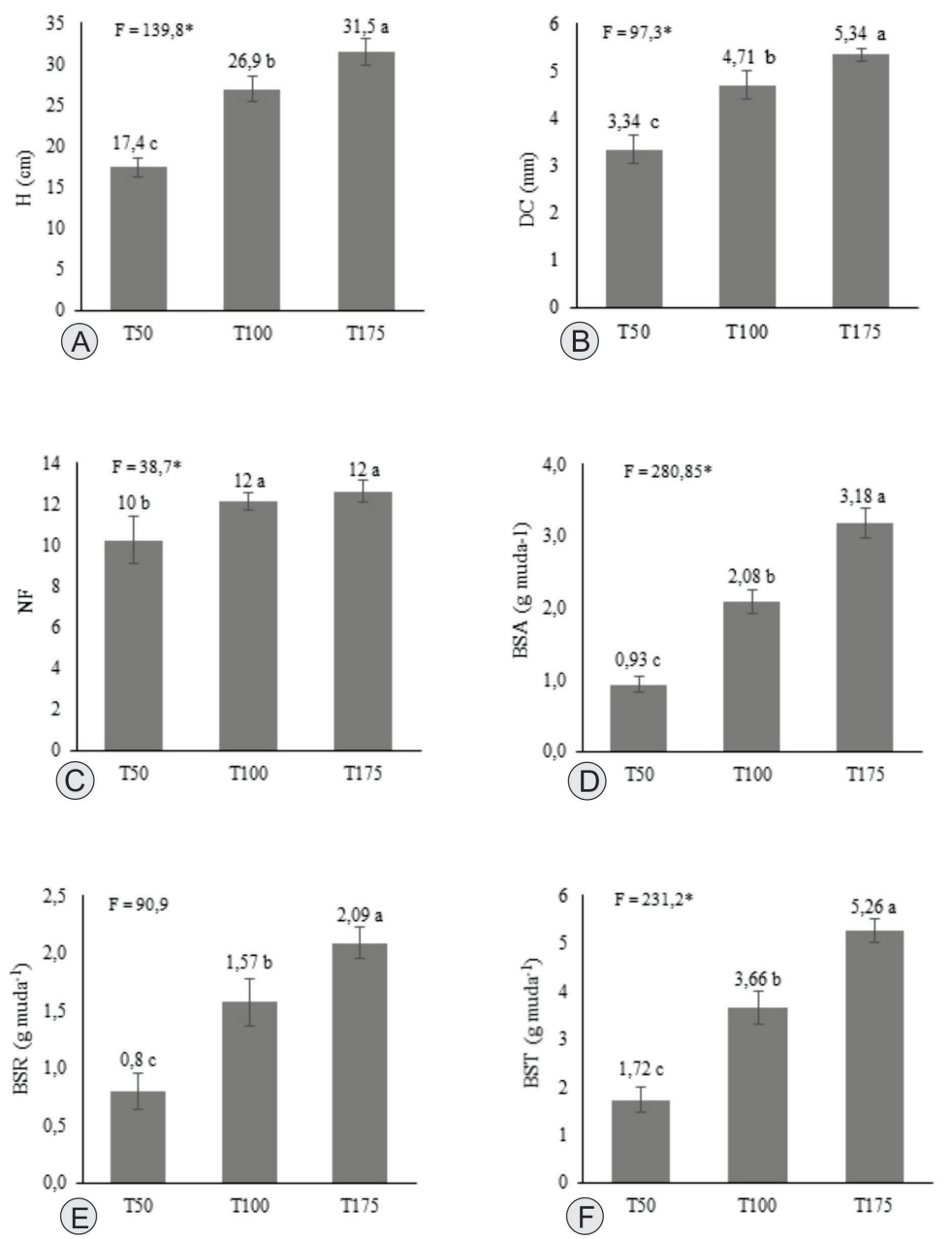

Figura 1. Parâmetros morfológicos de mudas de angico-vermelho aos 7 meses de idade. A - altura (H), B - diâmetro do colo (DC), C - número de folhas (NF), D - biomassa seca aérea (BSA), E -biomassa seca radicular (BSR), $\mathrm{F}$ - biomassa seca total (BST). 
Os resultados estão em consonância com estudos realizados em Hymenaea courbaril var. stilbocarpa (Hayne) Y.T.Lee \& Langenh., Tabebuia chrysotricha (Mart. ex DC.) Sandl., Parapiptadenia rigida (Ferraz \& Engel, 2011), e em Calophyllum brasiliense Cambess. e Toona ciliata M.Roem. (Lisboa et al., 2012). Os autores observaram uma relação direta entre o volume do substrato e crescimento da planta, onde presumidamente o aumento no volume favorece o crescimento das mudas em condições de viveiro.

As mudas procedentes dos recipientes com $50 \mathrm{~cm}^{3}$ tiveram os menores valores em todos os parâmetros avaliados. O pequeno volume de substrato, comenta Reis et al. (1989), reflete na diminuição da massa seca do sistema radicular e do número de radicelas que potencialmente influenciam na absorção de nutrientes, produzindo mudas de baixa qualidade, fato constatado nesse estudo (Figura 1). Ainda, segundo o autor, um sistema radicular altamente volumoso tende a apresentar maior número de ápices radiculares, região em que a raiz é mais eficiente na absorção e transporte de água e nutrientes e, sobretudo, na produção de reguladores de crescimento.

Os resultados mais promissores de crescimento em altura e diâmetro do colo foram verificados no $\mathrm{T} 175$, em virtude de seu maior volume de substrato e consequentemente menor restrição radicular imposta às plântulas. Segundo Carneiro (1995), a altura e o diâmetro do colo são características relevantes na avaliação da qualidade das mudas; normalmente aquelas com diâmetros mais elevados apresentam maior capacidade de emissão de novas raízes (Leles et al., 2001) e, assim, aumenta as possibilidades de sobrevivência às condições enfrentadas em campo.

Pesquisas realizadas com as espécies Pinus taeda L. (Carneiro, 1985), Pinus echinata Mill. (Brissette, 1990), Tabebuia serratifolia (Vahl) Nich., Copaifera longsdorffii Desf e Piptadenia peregrina L. Benth. (Gomes et al., 1990), mostraram respostas similares aos resultados encontrados neste estudo.

Gomes et al. (2003) descrevem que recipientes de maior capacidade volumétrica, normalmente tendem a disponibilizar maiores quantidades de nutrientes e água às mudas, além de limitar, em menores proporções, o crescimento das raízes, quando comparado com aqueles de tamanho inferior.

A altura considerada como ideal para as espécies florestais saírem da fase de viveiro para as condições de campo ainda é assunto controverso e altamente debatido. Schorn \& Formento (2003) recomendam uma altura entre 15 e $20 \mathrm{~cm}$ como apropriada para as mudas deixarem o viveiro e estarem aptas ao estabelecimento em campo. Nesse sentido, quando esta variável é levada em consideração isoladamente ao final deste experimento, todos os tratamentos estariam em plenas condições de plantio.

O padrão encontrado para o número de folhas (NF), coincide com trabalhos de Santos (1998), Fonseca et al. (2002) e José et al. (2005). Os autores reportam a importância dessa variável na formação de mudas de alta qualidade, pois a quantidade de folhas reflete diretamente em superfície foliar, aumentando a eficiência fotossintética e evapotranspiração.

$\mathrm{O}$ efeito significativo do tamanho dos tubetes e o ganho em massa seca das mudas, tanto da parte aérea (BSA) como do sistema radicular (BSR), é igualmente referido por Santos et al. (2000). Os autores analisam esses parâmetros isoladamente em Cryptomeria japonica (D. Don.) e mencionam que mudas maiores são obtidas nos recipientes com volumes maiores.

A interpretação dos resultados apresentados na figura 2 aponta que os tratamentos T100 e T175 promoveram maiores médias da relação altura/diâmetro do colo e o T50 resultou em valores inferiores. Nesse sentido, o tratamento T50 mostra-se mais rustificado em relação aos demais, uma vez que, segundo Carneiro (1983), quanto menor for o valor dessa relação, maior será a capacidade de as mudas sobreviverem e se estabelecerem no campo. No entanto, essa variável deve ser avaliada em conjunto com outros parâmetros, como, por exemplo, o Índice de Qualidade de Dickson, visto que, nas demais características avaliadas, o T50 não pode ser considerado o tratamento mais promissor.

Para a relação BSR/BSA, os tratamentos T100 e T175 não diferiram entre si, no entanto, foram distintos de T50. A formação de um maior volume de raízes auxilia na absorção de nutrientes e, por conseguinte, na formação de BSA em maior proporção. Estes resultados corroboram com a afirmação de Glass (1989), em que a razão aumenta à medida que se diminui o suprimento de nutrientes.

Quanto à relação H/BSA, o T175 foi o tratamento que promoveu maiores médias, seguido pelo T100 e T50. O tamanho da embalagem exerce influência nesta relação, afetando consideravelmente o crescimento em altura e a produção de matéria seca. Na prática, convenciona-se que quanto menor esse valor, maior será a capacidade de sobrevivência da muda. 

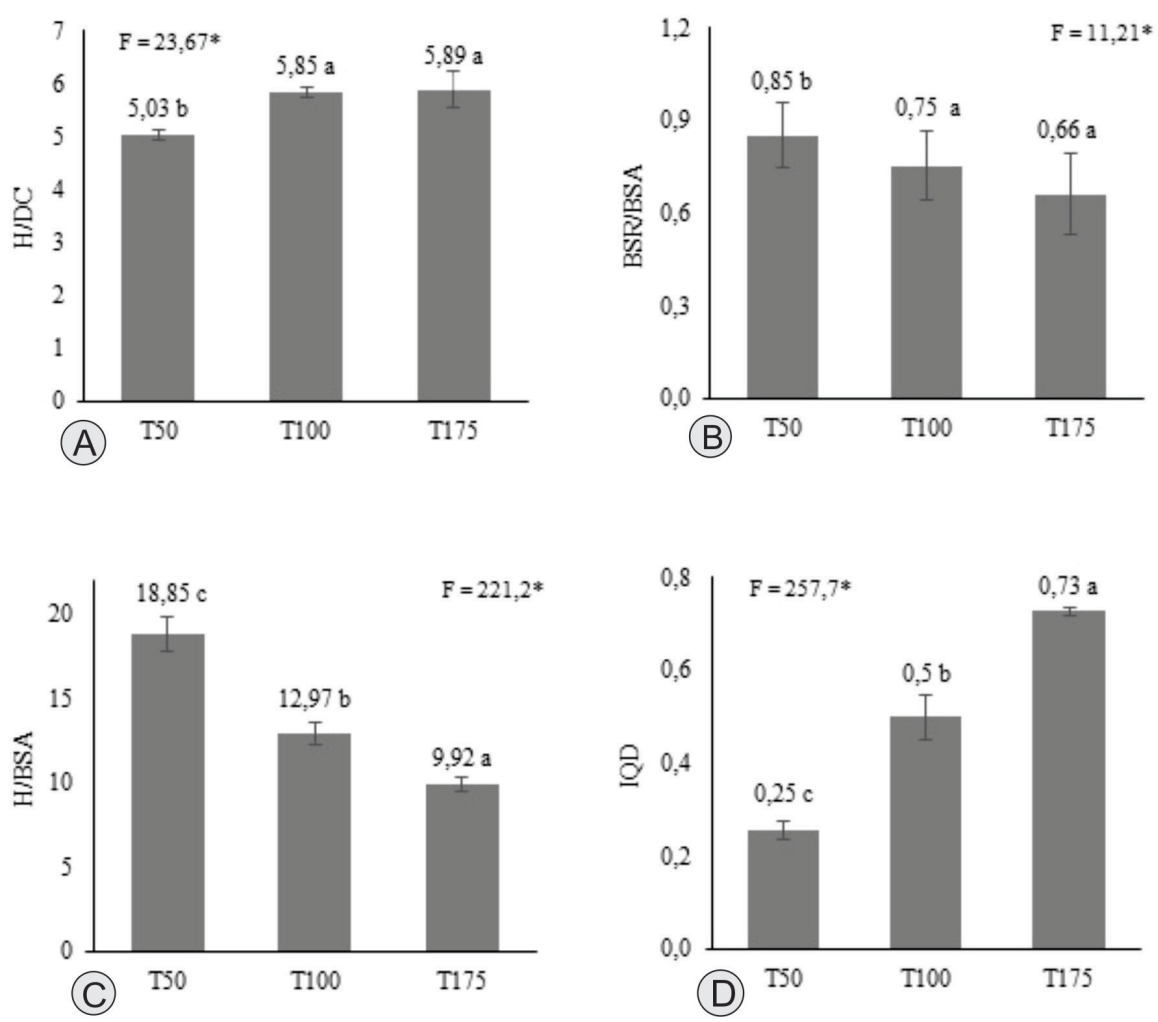

Figura 2. Relações obtidas em mudas de Parapiptadenia rigida em tubetes com diferentes capacidades volumétricas (T50, T100, T175). A - H/DC (altura/diâmetro do colo), B - BSR/BSA (biomassa seca radicular/biomassa seca aérea), C - H/BSA (altura/biomassa seca aérea), D - IQD (índice de qualidade de Dickson).

Os valores do índice de qualidade de Dickson (IQD) reforçam as diferenças entre os três tratamentos, com melhor qualidade das mudas produzidas no maior volume de recipiente. $\mathrm{O}$ resultado significativamente inferior do IQD no T50 corrobora as evidências de que as mudas produzidas nesses tubetes são de qualidade inferior.

\section{Conclusão}

Para a produção de mudas de angico-vermelho em viveiro, no período de sete meses, os resultados mais promissores para as variáveis altura, diâmetro do colo, biomassa seca aérea, biomassa seca radicular, biomassa seca total e índice de Qualidade de Dickson foram obtidos com tubetes de $175 \mathrm{~cm}^{3}$.

A menor dimensão de recipiente $\left(50 \mathrm{~cm}^{3}\right)$ limitou o crescimento das plantas, acarretando em mudas com qualidade inferior para o plantio em condições de campo. 


\section{Referências}

BRACHTVOGEL, E. L.; FREIBERGER, M. B.; MALAVASI, M. M.; MALAVASI, V. C. Efeitos do uso de um fertilizante de lenta disponibilidade e do volume do recipiente na formação de mudas de Peltophorum dubium. Scientia Agraria Paranaensis, Acrelandia, n. 1, v. 5, p. 67-71, 2006.

BRASIL. Ministério do Meio Ambiente, dos Recursos Hídricos e da Amazônia Legal. Primeiro relatório nacional para a Convenção sobre Diversidade Biológica: Brasil. Brasília, DF, 1998. 283 p.

BRISSETTE, J. C. Development and function of the root systems of southern pine nursery stock. In: SOUTHERN FOREST NURSERY ASSOCIATION, Biloxi, 1990. Proceedings. Biloxi: [Association], 1990. p. 67-81.

CARNEIRO, J. G. A. Efeito da densidade sobre o desenvolvimento de alguns parâmetros morfo-fisiológicos de mudas de Pinus taeda L. em viveiro e após plantio. 1985. 125 f. Tese (Concurso a Professor Titular) - Universidade Federal do Paraná, Curitiba.

CARNEIRO, J. G. A. Influência dos fatores ambientais, das técnicas de produção sobre o desenvolvimento de mudas florestais e a importância dos parâmetros que definem sua qualidade. In: BARROS, N. F. de (Coord.). Florestas plantadas nos neotropicos como fonte de energia: anais do Simpósio. Viçosa, MG: Universidade Federal de Viçosa, 1983. p. 10-24.

CARNEIRO, J. G. de A. Produção e controle de qualidade de mudas florestais. Curitiba: Universidade Federal do Paraná / FUPEF; Campos: Universidade Estadual do Norte Fluminense, 1995. 451 p.

DAVID, M. A.; MENDONÇA, V.; REIS, L. L.; SILVA, E. A.; TOSTAS, M. S.; FREIRE, P. A. Efeito de doses de superfosfato simples e de matéria orgânica sobre o crescimento de mudas de maracujazeiro amarelo. Pesquisa Agropecuária Tropical, v. 38, n. 3, p. 147-152, 2008.

DICKSON, A.; LEAF, A. L.; HOSNER, J. F. Quality appraisal of white spruce and white pine seedling stock in nurseries. Forestry Chronicle, v. 36, n. 1, p. 10-13, 1960.

DUMROESE, R. K.; DAVIS, A. S.; JACOBS. D. F. Nursery response of Acacia koa seedlings to container size, irrigation method, and fertilization rate. Journal of Plant Nutrition, v. 34, p. 877-887, 2011. DOI:10.1080/01904167.2011.544356

FERRAZ, A. V.; ENGEL, V. L. Efeito do tamanho de tubetes na qualidade de mudas de jatobá (Hymenaea courbaril 1. var. stilbocarpa (hayne) lee et lang.), ipê-amarelo (Tabebuia chrysotricha (Mart. ex DC.) Sandl.) e guarucaia (Parapiptadenia rigida (Benth.) Brenan). Revista Árvore, Viçosa, MG, v. 35, n. 3, p. 413-423, 2011. DOI: 10.1590/S0100-67622011000300005.

FONSECA, E. P; VALÉRI, S. V; MIGLIORANZA, E; FONSECA, N. A. N; COUTO, L. Padrão de qualidade de mudas de Trema micrantha (L.) Blume, produzidas sob diferentes períodos de sombreamento. Revista Árvore, Viçosa, MG, v. 26, n. 4, p. 516-523, 2002. DOI: $10.1590 / \mathrm{S} 0100-67622002000400015$

GLASS, A. D. M. Plant nutrition: an introduction to current concepts. Boston: Jones \& Bartlett Publishers, 1989. 234 p.
GOMES, J. M.; COUTO, L.; BORGES, R. C. G. Influência do tamanho da embalagem plástica na produção de mudas de Ipê, Copaíba e Angico Vermelho. Revista Árvore, Viçosa, MG, v. 14, n. 1, p. 26-34, 1990. DOI: 10.1590/S010067622010000200004

GOMES, M. J. COUTO, L.; LEITE, G. H.; XAVIER, A.; GARCIA, L. R. S. Crescimento de mudas de Eucalyptus grandis em diferentes tamanhos de tubetes e fertilização N-P-K. Revista Árvore, Viçosa, MG, v. 27, n. 2, p. 113-127, 2003. DOI: 10.1590/S010067622003000200001

JOSÉ, A. C.; DAVIDE, A. C.; OLIVEIRA, S. L. Produção de mudas de aroeira (Schinus terebinthifolius Raddi) para recuperação de áreas degradadas pela mineração de bauxita. Cerne, Lavras, v. 11, n. 2, p. 187-196, abr./jun. 2005.

LELES, P. S. S.; ARAUJO, C. G. J.; BRITO, N. A.; GUERRA, B. D. Crescimento e arquitetura radicial de plantas de Eucalipto oriunda de mudas produzidas em blocos prensados e em tubetes, após o plantio. Cerne, Lavras, v. 7, n. 1, p. 10-19, 2001.

LISBOA, C. A.; SANTOS, S. P.; OLIVEIRANETO, N. S.; CASTRO, N. D.; ABREU, M. H. A. Efeito do volume de tubetes na produção de mudas de Calophyllum brasiliense e Toona ciliata. Revista Árvore, Viçosa, MG, v. 36, n. 4, p. 603-609, 2012. DOI: 10.1590/ S0100-67622012000400003

LORENZI, H. Árvores brasileiras: manual de identificação e cultivo de plantas arbóreas nativas do Brasil. Nova Odessa: Plantarum, 2002. v. 1. 378 p.

REIS, G. G.; REIS, M. G. F.; MAESTRI, M. Crescimento de Eucalyptus camaldulensis, E. grandis e E. cloeziana sob diferentes níveis de restrição radicular. Revista Árvore, Viçosa, MG, v. 13, n. 1, p. 1-18, 1989.

SANTOS, C. B. Efeito de modelos de tubetes e tipo de substratos na qualidade de mudas de Cryptomeria japonica (L. F.) D. Don. 1998. 65 f. Dissertação (Mestrado em Engenharia Florestal) Universidade Federal de Santa Maria, Santa Maria, RS.

SANTOS, C. B.; LONGHI, S. J.; HOPPE, J. M. Efeito do volume de tubetes e tipos de substrato na qualidade de mudas de Cryptomeria japônica (L.F.) D.Don. Ciência Florestal, Santa Maria, RS, v. 10, n. 2, p. 1-15, 2000.

SANTOS, H. G. dos; JACOMINE, P. K. T.; ANJOS, L. H. C. dos; OLIVEIRA, V. A. de; LUMBRERAS, J. F.; COELHO, M. R.; ALMEIDA, J. A. de; CUNHA, T. J. F.; OLIVEIRA, J. B. de. Sistema brasileiro de classificação de solos. 3. ed. Brasília, DF: Embrapa, 2013. 353 p.

SCHORN, L. A.; FORMENTO, S. Silvicultura II: produção de mudas florestais. Blumenau: FURB, 2003. 58 p.

VACCARO, S.; LONGHI, S. J.; BRENA, D. A. Aspectos da composição florística e categorias sucessionais do estrato arbóreo de três subseres de uma floresta estacional decidual, no Município de Santa Tereza - RS. Ciência Florestal, Santa Maria, RS, v. 9, n. 1, p. 1-18, 1999. 